\title{
Talipes equinovarus (clubfoot): neglected for 47 years and subsequent treatment
}

\author{
Garry Shtofmakher, ${ }^{1}$ Roger Lee Kilfoil Jr, ${ }^{1}$ Adam Rozenstrauch, ${ }^{1}$ Thomas Vitale ${ }^{2}$
}

${ }^{1}$ New York College of Podiatric Medicine, New York,

New York, USA

${ }^{2}$ Department of Surgery,

New York College of Podiatric Medicine, New York,

New York, USA

\section{Correspondence to} Garry Shtofmakher, gshtofmakher@nycpm.edu

Accepted 3 May 2014

\section{CrossMark}

\footnotetext{
To cite: Shtofmakher $\mathrm{G}$, Kilfoil RL, Rozenstrauch $\mathrm{A}$, et al. BMJ Case Rep Published online: [please include Day Month Year] doi:10.1136/bcr-2014205395
}

\section{DESCRIPTION}

A 47-year-old white woman presented to the podiatry clinic with congenital bilateral residual talipes equinovarus (TEV). The condition progressively worsened as her job requires her to stand for extended periods of time. The patient states that she has increased symptoms of pain in her hallux of the right foot as well as generalised foot pain bilaterally. The patient recalls having corrective surgery as a child. She was offered further surgical correction during adulthood but declined. The patient takes no medication and has no systemic conditions. There is no family history of TEV. The patient admits to being born prematurely. Vascular and neurological examinations were unremarkable. Clinical observation (video 1), radiographs (figures 1 and 2), plantar pressure analysis (F-Scan; video 2) and a gait examination (video 3) were performed. Significant findings were residual TEV bilaterally, a dorsal bunion and rigidly contracted hallux on the right. Orthopaedics dispensed bilateral accommodative shoe inserts made from $1 / 4^{\prime \prime}$ white plastazote and $1 / 16^{\prime \prime}$ pink plastazote and bilateral below-inlay heel lifts made from $1 / 4^{\prime \prime}$ felt were provided to the patient. The patient relayed immediate improvement of symptoms on ambulation. The patient was further informed that controlling the first ray will be difficult, and eventual surgical intervention may be needed.

TEV occurs in approximately 1/1000 live-births, with bilateral deformities in approximately $50 \%{ }^{1}$ Failure of treatment is the main aetiology of residual TEV. $^{1}$ Recognition of the residual adult TEV deformity requires the presence of fixed cavus, adductus, varus and equines. ${ }^{1} \mathrm{~A}$ dorsal bunion is caused by an imbalance between tibialis anterior and peroneus longus, and is often iatrogenically induced

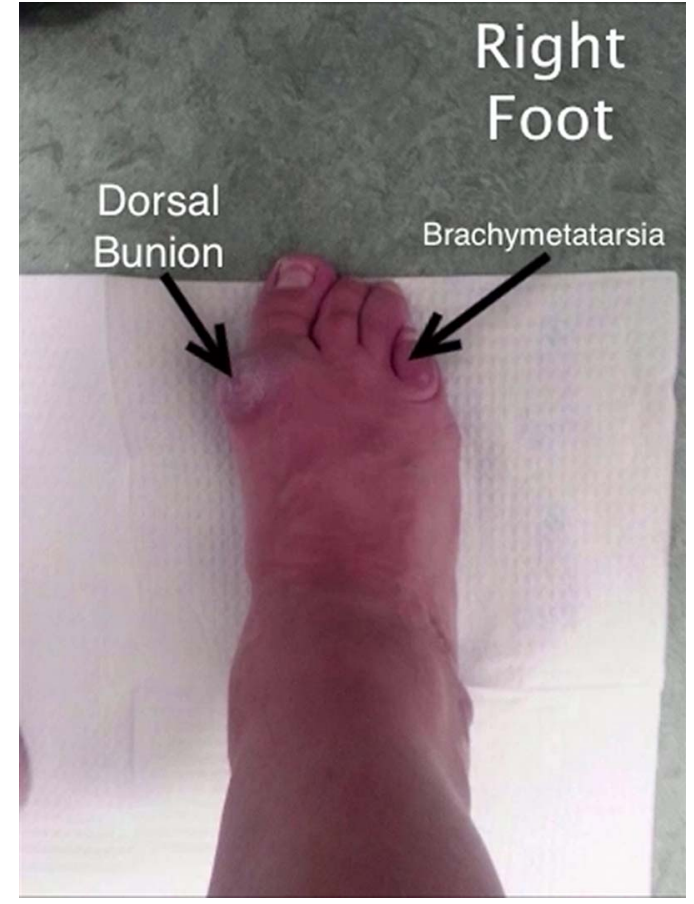

Video 1 Physical examination was performed starting from the right foot. The examination indicated bilateral $T E V$, adducto-varus deformity of both $5^{\text {th }}$ digits with remaining digits contracted, and a dorsal bunion with a palpable dorsal bursa on the right $1^{\text {st }}$ metatarsal head. The right hallux was rigidly contracted at the $1^{\text {st }}$ MTPJ. The ankle, subtalar, and midtarsal joints of the right were rigid, and semi-flexible on the left. Healed lateral and medial "J" shaped incisions are noted on the foot and ankle bilaterally.

due to overcorrection. ${ }^{2}$ Examination consists of a thorough musculoskeletal, radiographic and gait examination. ${ }^{1}$ Non-surgical approaches have been

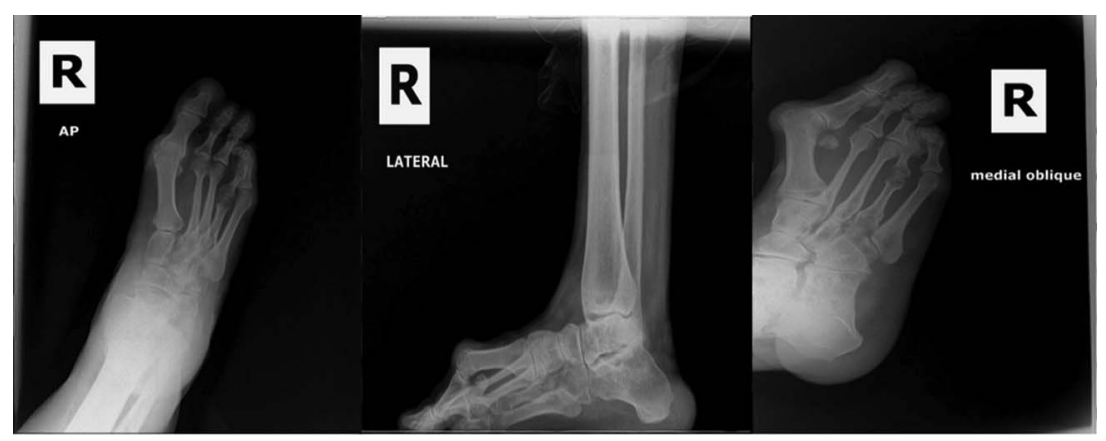

Figure 1 Weight-bearing anteroposterior (AP) radiograph of the right foot-congenital brachymetatarsia of the fourth metatarsal is evident. The fifth digit is significantly contracted in the medial direction. A bunion deformity is also evident with complete obliteration of the joint space at the first metatarsalphalangeal joint. Weight-bearing lateral radiograph of the right foot-first ray elevatus with hallux equinus is evident. Evidence of flattening of the talar dome with degenerative changes in the ankle and subtalar joints identified. A cavus foot type is noted. Weight-bearing medial oblique radiograph of the right foot-congenital brachymetatarsia of the fourth metatarsal is evident. The dorsal bunion is especially prominent in this view. 


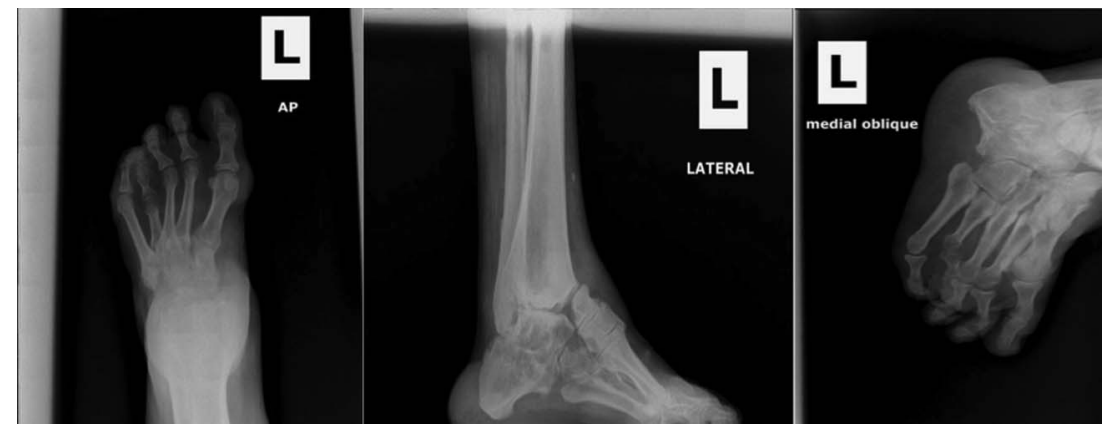

Figure 2 Weight-bearing anteroposterior (AP) radiograph of the left foot-congenital brachymetatarsia of the fourth metatarsal is evident. The fifth digit is significantly contracted in the medial direction. A bunion deformity is also evident. Soft tissue swelling is evident in the rearfoot. Weight-bearing lateral radiograph of the left foot-severe degenerative changes are noted in the rearfoot, with erosion of the talar body and head. There is ankylosis of the talar body to the calcaneus and the distal tibia. The calcaneus, distal tibia and navicular are eroded. There is an articulation of the navicular with the distal tibia. A phlebolith is noted in the dorsum of the leg. A prominent cavus foot type is noted. Weight-bearing medial oblique radiograph of the left foot-congenital brachymetatarsia of the fourth metatarsal is evident. Erosion of the navicular is noted.

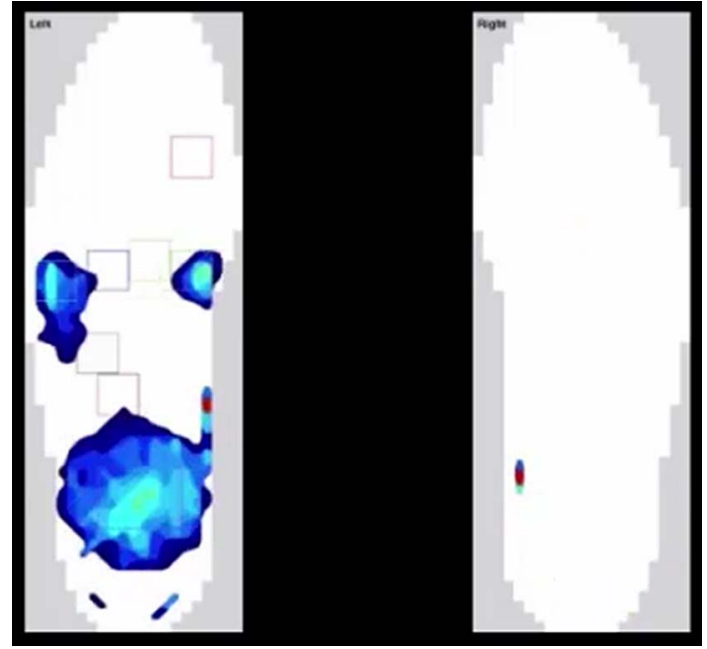

Video 2 Dynamic In-shoe plantar pressure analysis (Tethered Tekscan $®$ F-Scan $®$ System) was performed with the patient ambulating at her self-selected cadence in her everyday sneakers (Nike® Dart 10) across a flat 8.5 meter walkway. Plantar pressure analysis indicated the absence of ground contact of the distal medial column of the right foot due to the dorsal bunion.

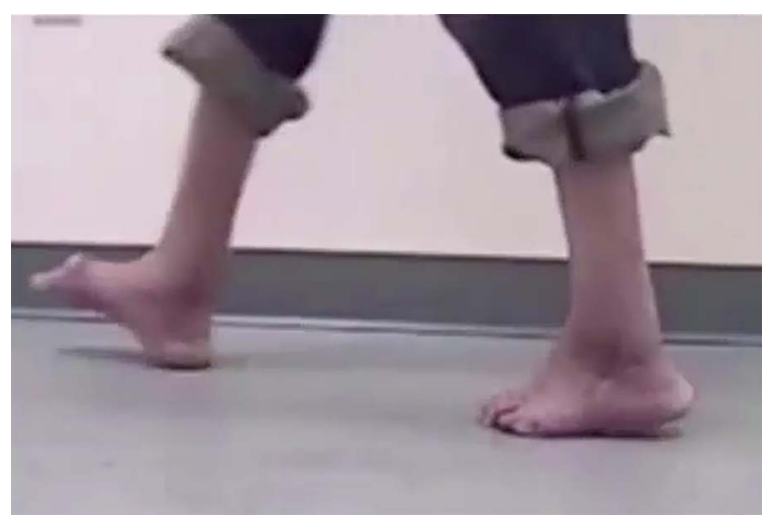

Video 3 A gait examination was performed with the patient ambulating barefoot at her self-selected cadence across a flat 8.5 meter walkway. An altered gait pattern was noted. There was a lack of ankle mobility during midstance on the left side. The dorsal bunion on the right foot resulted in the first ray remaining non-weight-bearing throughout the gait cycle. described for adult TEV. ${ }^{1}$ Surgical approaches utilise the specific deformities to select the procedure of choice. ${ }^{1}$ Both the approaches aim to achieve a plantar-grade foot. ${ }^{1}$ Negative sequelae of adult TEV can be avoided with early intervention. ${ }^{3}$

\section{Learning points}

- The consequences of untreated talipes equinovarus (TEV) can lead to adaptive and degenerative changes in the structure of the foot.

- There are surgical and non-surgical options available for the treatment of residual adult TEV.

- Recognition of this deformity coupled with serial manipulations, casting and bracing in the first years of life can prevent residual adult TEV. However, an iatrogenically induced dorsal bunion can lead to symptoms later in life.

Acknowledgements The authors extend a gracious thank you to Dr Jeffrey J Cusack, DPM, for providing his expertise in biomechanics and gait analysis in the development of this case report.

Competing interests None.

Patient consent Obtained.

Provenance and peer review Not commissioned; externally peer reviewed.

\section{REFERENCES}

1 Walling AK. The adult clubfoot (congenital pescavus). Foot Ankle Clin 2008;13:307-14, vii.

2 Zide JR, Myerson M. The overcorrected clubfoot in the adult: evaluation and management-topical review. Foot Ankle Int 2013;34:1312-18.

3 Colburn M, Williams M. Evaluation of the treatment of idiopathic clubfoot by using the Ponseti method. J Foot Ankle Surg 2003;42:259-67. 
Copyright 2014 BMJ Publishing Group. All rights reserved. For permission to reuse any of this content visit http://group.bmj.com/group/rights-licensing/permissions.

BMJ Case Report Fellows may re-use this article for personal use and teaching without any further permission.

Become a Fellow of BMJ Case Reports today and you can:

- Submit as many cases as you like

- Enjoy fast sympathetic peer review and rapid publication of accepted articles

- Access all the published articles

- Re-use any of the published material for personal use and teaching without further permission

For information on Institutional Fellowships contact consortiasales@bmjgroup.com

Visit casereports.bmj.com for more articles like this and to become a Fellow 